\title{
Determinates of inner city butterfly and bee species richness
}

\author{
Kevin C. Matteson • Gail A. Langellotto
}

Published online: 31 March 2010

(C) The Author(s) 2010. This article is published with open access at Springerlink.com

\begin{abstract}
Although urbanization is increasing worldwide, relatively few studies have investigated patterns of urban biodiversity outside of city parks and reserves, in urban neighborhoods where people live and work. We evaluated models including local and landscape factors that might influence the bee and butterfly richness of community gardens located within densely populated neighborhoods of the Bronx and East Harlem in New York City $\left(>10,000\right.$ people $\left./ \mathrm{km}^{2}\right)$. The gardens were surrounded by buildings and limited amounts of green space (3,600-17,400 building units and 10-32\% green space within a $500 \mathrm{~m}$ radius). Contrary to our initial prediction that landscape green space might be especially influential in this heavily urbanized setting, the most highly supported models for both bee and butterfly richness (based on Akaike Information Criterion) included just the local, within-garden variables of garden floral area and sunlight availability. There was marginal support for models of bee richness including the number of building units surrounding gardens within a $500 \mathrm{~m}$ radius (which exhibited a negative association with bee richness). In addition, perhaps because bees are central place foragers that may nest within or near gardens, supported models of bee species richness also included total garden area, canopy cover, and the presence of wild/unmanaged area in the garden. Generally, our findings indicate that sunlight and floral abundance are the major factors limiting local pollinator diversity in this setting. This suggests that rooftop and other "open" urban habitats might be managed to increase local pollinator diversity, even if seemingly "isolated" within heavily developed neighborhoods.
\end{abstract}

Keywords Community gardens · New York City · Green space · Urban biodiversity · Modeling species richness

K. C. Matteson $(\bowtie) \cdot$ G. A. Langellotto

Department of Biological Sciences, Fordham University, Rose Hill Campus, Bronx, NY 10458, USA e-mail: Matteson@fordham.edu

G. A. Langellotto

Department of Horticulture, Oregon State University, 4017 Agriculture and Life Sciences Building, Corvallis, OR 97331, USA 


\section{Introduction}

Urban areas are expanding worldwide (United Nations Population Division 2006), resulting in habitat alterations that are spatially vast (McKinney 2002). The changes associated with urbanization often alter the composition and distribution of a variety of species (McKinney 2008), including insects (McIntyre 2000). Specifically, native invertebrate diversity generally decreases with increasing urbanization, especially in central urban core areas (McKinney 2008). In addition, prevalence of generalist and/or exotic species tends to increase in heavily developed neighborhoods, which may alter the composition of functionally important groups, such as pollinating insects (Kitahara and Fujii 1994; Clark et al. 2007; Di Mauro et al. 2007; Matteson et al. 2008). Despite these difficulties, small urban habitats in densely populated neighborhoods have the potential to facilitate reconnection of humans and nature (Miller 2005), and provide ecosystem services to the urban populace (Bolund and Hunhammar 1999). Indeed, urban habitats located in the most densely populated neighborhoods may provide the greatest benefit to the most people but, ironically, are the most likely to suffer from biotic homogenization and reduced native species richness (McKinney 2006). Despite the potential value of small urban habitats (Bolund and Hunhammar 1999), relatively few studies have investigated the factors governing biodiversity in heavily developed and densely populated neighborhoods.

Human management of urban land may exert a profound influence on biodiversity of pollinating insects, both by determining the diversity of vegetation types and the abundance of floral resources. In addition, local species richness may be influenced by landscape-level variables external to urban habitats, such as the proportion or diversity of habitat in the surrounding landscape (Levins 1969; McIntyre and Hostetler 2001; Clark et al. 2007; Di Mauro et al. 2007; Öckinger et al. 2009). Urban vegetation is distributed among fragmented and heavily managed gardens, parks, greenways, and other green spaces, all of which may facilitate movement of insects and other wildlife, and increase local species richness. Conversely, densely populated neighborhoods often contain tall buildings that may limit insect richness by obstructing dispersal and/or reducing sunlight (Ruszczyk and De Araujo 1992).

New York City is the largest urban area in the United States, with 8.2 million people living in five boroughs (United States Census Bureau 2006). Within the city, there are over 700 community gardens (Council on the Environment of New York City 2006), most of which are open to the public and rely on the direct involvement of local citizens as garden managers. Many community gardens are located in high density and low income neighborhoods (Matteson 2007), providing an opportunity to evaluate biodiversity in an inner city environment. Specifically in the neighborhoods of this study (located in the central Bronx, and East Harlem in Manhattan), more than $70 \%$ of the land area is composed of buildings, sidewalks, roads, and other paved areas, and human density is 19,000 people/ $\mathrm{km}^{2}$ and 15,000 people $/ \mathrm{km}^{2}$, respectively (New Yorkers For Parks 2005). For this study, we investigated the relative influence of local and landscape variables on bee and butterfly species richness in community gardens located in these neighborhoods. We hypothesized that, in addition to local variables such as floral area, landscape variables (i.e., green space and building density) would strongly influence local species richness.

In addition to contributing to a theoretical understanding of factors influencing insect biodiversity at the far end of the spectrum of urbanization, this study has several practical implications. First, a variety of crops grown in community gardens and other urban green spaces are known to be dependent on (e.g. cucumbers, squashes) or to benefit from (e.g. tomatoes, raspberries) insect pollination (Matteson and Langellotto 2009). Therefore, a 
diversity of pollinating insects may increase crop yield and contribute to urban agriculture, providing food security for residents of inner city neighborhoods. For example, the floral area of urban gardens was positively associated with deposition of conspecific pollen in cucumbers (Werrell et al. 2009), presumably because increased floral cover attracted a greater number of pollinators into urban gardens. Second, gardens include a variety of flowering plants (e.g. zinnias, marigolds, sunflowers, mint, basil, and more), some of which may be utilized by insects for pollen, nectar or both. These floral resources may be especially important for bees and butterflies moving through, or living within, developed urban landscapes where there are few alternate food resources. Finally, as mentioned above, the presence of "charismatic microfauna" (Connor et al. 2003), such as bees and butterflies, provides humans with opportunities for interaction with nature, potentially preventing what has been termed the "extinction of ecological experience" (Pyle 1978; Miller 2005) within urban neighborhoods.

\section{Study location and methods}

\section{Community garden study sites}

The 18 community gardens of this study were located in the central Bronx and East Harlem (Fig. 1) and varied in size (see Results), management and vegetative characteristics. Some gardens were managed primarily for the production of vegetables; others were used for non-

\section{Harlem Gardens}

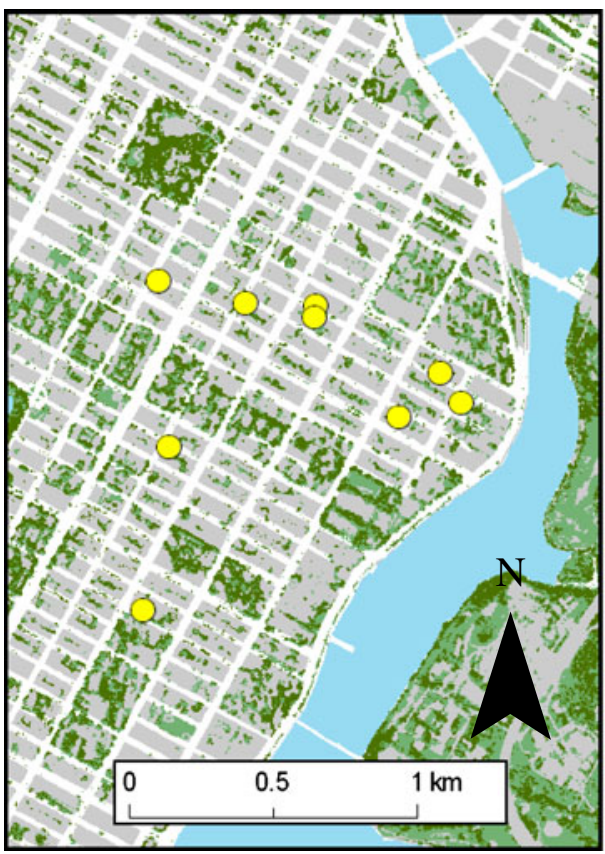

Bronx Gardens

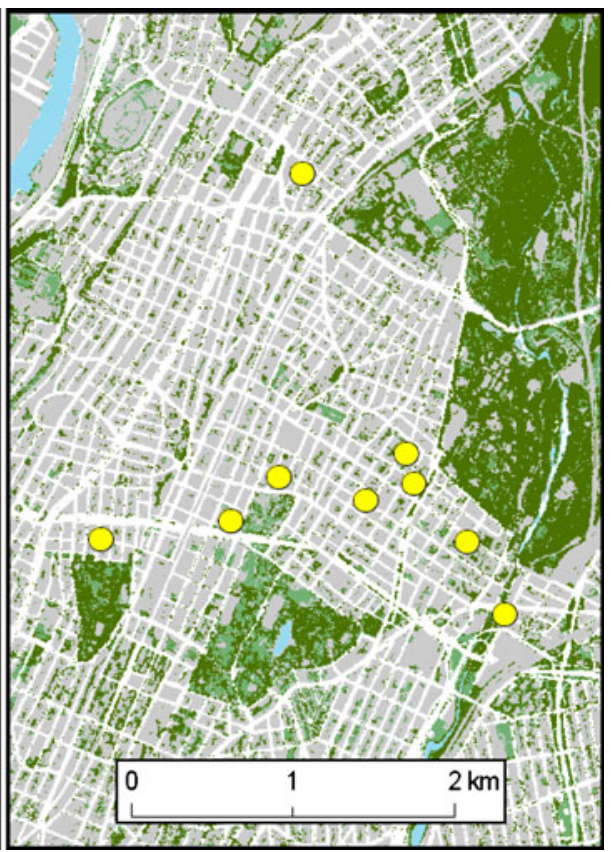

Fig. 1 Map of the locations (yellow circles) of 18 urban community gardens in East Harlem and the Bronx, New York City (note different spatial scales). The map was created using data provided by the USDA Forest Service, Northeastern Research Station 
gardening recreation. Common crop plants grown in these community garden study sites include hot and sweet peppers, mints and other herbs, kale and collards, tomatoes and tomatillos, strawberries, and cucumbers (for the full list, see Matteson and Langellotto 2009). Specific locations (street addresses and GPS coordinates) of these gardens are presented in Matteson et al. (2008).

Local (within garden) variables

For each garden, we measured the following variables: total garden area, vegetable area, floral area, wild/unmanaged area, tree canopy cover, shrub cover, lawn area, area of paths/ structures, garden age, and sunlight availability. We calculated garden age as the number of years from the creation of the garden (when soil and plants were added to a formerly abandoned lot) to 2003 (the first year of the study). Sunlight availability of individual gardens was measured using a photometer (Gempler's 4 in 1 Weather Meter, Gempler's, Madison, WI, USA). To account for daily and seasonal changes in sunlight availability, we used the average of 30 sunlight measurements taken at different times, days, and in different locations within each garden. Because bee and butterfly species vary in host plant and/or nesting substrate requirements, species richness might increase with the total diversity of land uses within the garden. Therefore, we used the Shannon Index to compute two measures of heterogeneity of land use within gardens. One heterogeneity measure (gardenH) included the proportion of seven within-garden land uses (vegetable area, floral area, wild/unmanaged area, tree canopy cover, shrub cover, lawn area, and area of paths/ structures). A second measure (vegH) omitted the contribution of paths/structures and mowed lawn area to garden heterogeneity, which we believed would provide few resources for most pollinators.

\section{Landscape variables}

We assessed the proportion of green space surrounding individual gardens using a high spatial resolution map of New York City provided by David Nowak of the USDA Forest Service, Northeastern Research Station. The map included four land cover types (tree/ shrub, grass/herbaceous, impervious surface, and water) with a pixel-size of $0.81 \mathrm{~m}^{2}$, which were generated using a hybrid classification method (Myeong et al. 2001) applied to high resolution aerial photography taken in 2001 and 2002. In addition to large parks, this map included relatively small, vegetated areas of the city (i.e., street trees, vacant lots, community gardens, vegetated margins along roads, grass, and trees on the grounds of housing projects, etc.), which may contribute to butterfly and bee species richness.

We quantified the number of "building units" surrounding gardens, using a 2001 municipal data set provided by CENYC (Council on the Environment of New York City 2006). Building units include all residential, commercial, and office spaces in a building, providing a proxy for the vertical and horizontal spatial extent of buildings in the vicinity of the gardens. Tall buildings in the vicinity of the gardens often contained over 100 total building units, including commercial units on the ground level and multiple residential units above.

We used the buffer and clip toolbox functions in ArcDesktop 9.3 to quantify the number of building units and green space (combined tree/shrub and grass/herbaceous cover) surrounding each garden in circles with a $200 \mathrm{~m}$ radius and a $500 \mathrm{~m}$ radius. These distances were chosen because they generally correspond to the average daily movements of many butterflies (Scott 1975) and typical foraging distances of many bees (Gathmann and Tscharntke 2002; Greenleaf et al. 2007). Although some bees (e.g. bumble bees, Xylocopa 
virginica, Apis mellifera) (Greenleaf et al. 2007) and some butterflies (Öckinger et al. 2009) are capable of larger movements, we did not analyze green space surrounding gardens at larger spatial scales because we wanted to minimize spatial overlap among gardens. In addition, we were reluctant to conduct additional analyses that would increase the likelihood of erroneous results (i.e. Type I error), especially considering that measures of landscape connectivity are often highly correlated (Winfree et al. 2005).

Butterfly and bee sampling

We observed butterflies in community gardens weekly from July through September in 2003 and June through September in 2004 and 2005. Bees were sampled using handnetting (once per month in May, June, July and August 2005 and 2006) and 355-ml yellow bowl traps (bowls: $15 \mathrm{~cm}$ in diameter, $4.5 \mathrm{~cm}$ in depth, Solo Cup Company, Urbana, IL; detergent: $4 \mathrm{ml}$ per bowl, Colgate-Palmolive Company, New York, NY) which were set twice a month from July to September in 2003 and May to September in 2004 and 2005. To reduce disturbances within these heavily trafficked gardens, bowls were clearly labeled as research (on the underside and lip of the bowl), suspended from trees, shrubs, or along fences $(\sim 1.5-2.5 \mathrm{~m})$, and left out for just $24-48 \mathrm{~h}$ (same duration for all gardens) during calm weather conditions. Although this bowl trapping methodology differs from the standardized bee inventory plot (http://online.sfsu.edu/ beeplot/) (we were not aware of this protocol at the onset of the project), the cumulative number of traps collected in this study $(>8,000)$ and the use of species richness estimators (see below) should ensure that the richness of bees and butterflies was sufficiently described. On each sampling date, for every $600 \mathrm{~m}^{2}$ of garden area, we collected one yellow bowl trap, conducted $5 \mathrm{~min}$ of butterfly counts, and/or spent $10 \mathrm{~min}$ hand-netting bees. We scaled sampling effort to garden area in this manner because our goal was to assess the relative influence of local and landscape variables on species richness per garden (rather than per standardized unit area). All gardens were sampled the same number of days per year.

Butterflies were identified using Brock and Kaufman (2003). Following Clark et al. (2007) we classified butterflies by feeding specificity (broad vs. restricted), broods per year, and number of larval host plants used ( $>10$ or $\leq 10$ species). The number of broods per year, specific to the New York City area, was determined using Cech (1991). Habitat specificity and number of larval plants followed Clark et al. (2007) or, for butterflies unique to this study, Cech and Tudor (2005). The ecological characteristics of bees found in the gardens of this study are discussed separately in Matteson et al. (2008). Many bees in the genus Lasioglossum were identified by Sam Droege of the U.S. Geological Survey. All other bees were identified by John S. Ascher of the American Museum of Natural History, where a synoptic collection is maintained.

To determine total species richness (pooled across all sampling dates) in each of the 18 sampled gardens, we used EstimateS software (Version 8.0, R. K. Colwell, http://purl.oclc. org/estimates) to calculate Chao1 (for bees) and Chao2 (for butterflies) nonparametric species richness estimators. Chao 2 is based on the incidence of species across sampling dates and thus can be used when a single, standardized sampling method is utilized, as was the case for our sampling of butterflies (bowl sampling was not used for butterflies). Because our sampling protocol for bees involved two separate sampling protocols (both bowl trapping and hand-netting), we used the Chaol estimator, which is based on abundance of species relative to each other, rather than incidence of species across sampling dates. Both Chao estimators have been demonstrated to be more precise and less biased than using observed species richness or several other estimators (Brose and Martinez 2004; Walther and Moore 2005). 
Assessing predictors of insect species richness in urban gardens

We measured 12 local, within-garden variables and four surrounding landscape variables for each garden of this study (Table 1). We constructed models including variables that we considered, a priori, to be most likely to have an impact on insect diversity in this setting. These included total garden area, floral area, and sunlight, all of which are widely known to influence bee and butterfly richness. Canopy cover and wild/unmanaged area per garden also were included because we believed that these variables might correlate with nest site availability (for bees) or host plants (for butterflies). The two measures of vegetation heterogeneity (gardenH and vegH) and garden age were evaluated because we believed diversity of plant types or colonization time might influence insect diversity. Finally, we included each of the four landscape variables (green space and number of building units at the $200 \mathrm{~m}$ and $500 \mathrm{~m}$ radius scales), resulting in a total of 12 candidate variables that we believed might influence bee or butterfly species richness.

To avoid data mining among so many independent variables and stepwise procedures that are prone to erroneous conclusions (Burnham and Anderson 1998), we utilized an objective approach to model selection. First, we used hierarchical partitioning (rand.hp function in the hier.part package of $\mathrm{R}$ statistical program 2.8.1) to identify the independent (uncorrelated) explanatory strength of each individual variable (for details regarding this procedure, see Mac Nally 2002). We then ranked all variables according to their Z-scores (Fig. 2), which indicate the independent influence of each variable on butterfly or bee species richness. Next, we constructed a global model that included all 12 independent variables for both butterfly and bee species richness. Each global model explained the majority of variation in species richness (unadjusted $R^{2}$ of 0.814 for butterfly richness and 0.900 for bee richness). Therefore, we proceeded to construct models of increasing simplicity (i.e., 11 variables, 10

Table 1 Values of local (within-garden) and surrounding landscape variables of the urban community gardens $(n=18)$ of this study. Please refer to the methods for descriptions of all garden variables. Note that "green space" in this study largely consisted of parks, gardens and other human-managed sites, rather than forests or other forms of "less disturbed" habitat

\begin{tabular}{lllcc}
\hline & Variable & Units & Mean \pm SD & Range \\
\hline Local variables & Total garden area & Meters ${ }^{2}$ & $909 \pm 541$ & $224-2,188$ \\
& Vegetable area & $\%$ & $23 \pm 17$ & $0-71$ \\
& Floral area & $\%$ & $12 \pm 9$ & $1-40$ \\
& Wild/unmanaged area & $\%$ & $11 \pm 21$ & $0-90$ \\
& Tree canopy cover & $\%$ & $27 \pm 15$ & $1-71$ \\
& Shrub cover & $\%$ & $5 \pm 4$ & $0-13$ \\
& Lawn area & $\%$ & $19 \pm 24$ & $1-80$ \\
& Area of paths/structures & $\%$ & $35 \pm 26$ & $0-33$ \\
& Garden age & Years & $13 \pm 9$ & $21,000-81,000$ \\
& Sunlight & Mean lux & $61,000 \pm 20,000$ & $0.77-1.72$ \\
& GardenH & Shannon Index & $1.38 \pm 0.25$ & $0.66-1.58$ \\
& VegetationH & Shannon Index & $1.19 \pm 0.26$ & $0.08-0.23$ \\
Green space $(200 \mathrm{~m})$ & Proportion & $0.15 \pm 0.05$ & $0.10-0.32$ \\
Green space $(500 \mathrm{~m})$ & Proportion & $0.21 \pm 0.05$ & $74-473$ \\
& Building units $(200 \mathrm{~m})$ & Number & $201 \pm 113$ & $3,600-17,400$ \\
Building units $(500 \mathrm{~m})$ & Number & $10,100 \pm 4,200$ &
\end{tabular}


a

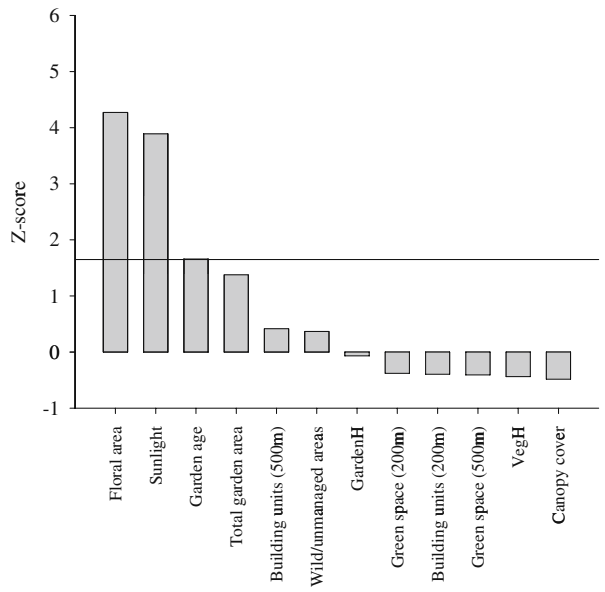

b

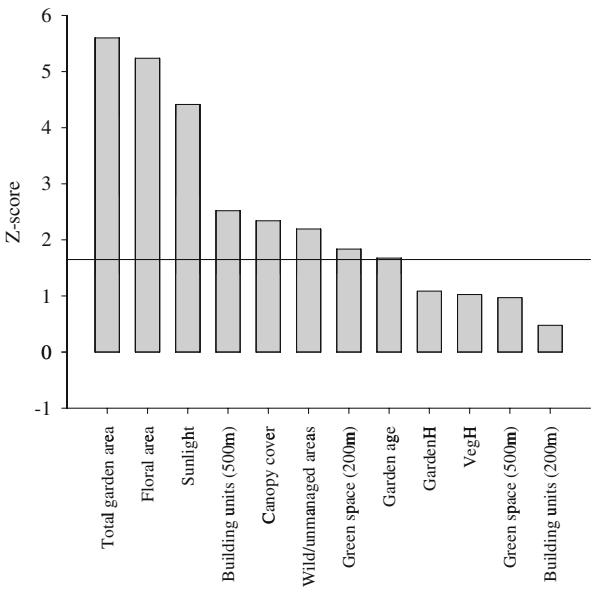

Fig. 2 Plot of Z-scores for independent contributions (from 100 randomizations of the data matrix) from potentially explanatory predictor variables of butterfly species richness (Panel A) and bee species richness (Panel B). Z-scores above the reference line of 1.65 indicate significance at the $95 \%$ confidence level (Mac Nally 2002)

variables, etc.) by sequentially dropping independent variables with the lowest Z-score (least independent influence on the dependent variable) as identified by hierarchical partitioning. We used least squares regressions (Systat 2004) to generate each of the 12 models. Akaike's Information Criterion with a correction for small sample size $\left(\mathrm{AIC}_{\mathrm{c}}\right)$ (Hurvich and Tsai 1989) was used to identify the most informative and parsimonious models (Burnham and Anderson 1998) for the two diversity measures. To enable comparison among models, evidence ratios were calculated as the ratio of two competing models' Akaike weights (Burnham and Anderson 1998). We considered an evidence ratio greater than 2.7 (which is equivalent to $\Delta \mathrm{AIC}_{\mathrm{c}}>2$ ) to indicate a better model (Burnham and Anderson 1998).

To increase normality, the following variables were $\log _{10}$-transformed: total garden area, the number of building units at the $200 \mathrm{~m}$ and $500 \mathrm{~m}$ scale, Chaol bee species richness, and Chao2 butterfly richness. Also to improve normality, vegetable area and tree canopy area per garden were square-root transformed, sunlight availability was cubed and green space proportions were arcsine square-root transformed (Sokal and Rohlf 1995). After transformation, all above independent and dependent variables did not significantly deviate from a normal distribution (Shapiro-Wilk's test, $p>0.05$ for all variables). The amount of wild/unmanaged area was not normally distributed because nearly half of the gardens had no wild/unmanaged space in the garden. Therefore, we characterized gardens with a dummy variable based on whether or not they contained any wild/unmanaged areas. The DurbinWatson test indicated that all models met assumptions of linearity and homoscedasticity.

\section{Results}

Garden characteristics and insect composition

The community gardens of this study were created fairly recently (mean of 13 years old) and were relatively small (mean area of $909 \mathrm{~m}^{2}$; range of 224-2,188 $\mathrm{m}^{2}$ ) (Table 1). At the $500 \mathrm{~m}$ scale, just $21 \%$ of the landscape surrounding gardens consisted of vegetation (range of 10 
$32 \%$ ), whereas there was a mean of over 10,000 building units (range of 3,600-17,400) (Table 1). Within gardens, the largest use of land was paths/structures (mean $=35 \%$ of garden area), followed by vegetable beds (23\%), lawn (19\%), and floral area (12\%). Gardens were largely open, with tree canopy covering just over a quarter of garden area $(27 \%)$, on average.

Over 3 years, we documented 3745 individual butterflies, representing 24 species/taxa, in these gardens (Table 2). The introduced cabbage white butterfly (Pieris rapae) was found in all gardens and was by far the most common butterfly. Other common butterflies included spring azures, Celastrina ladon spp. and red admirals, Vanessa atalanta. Most of the 24 butterfly species/taxa observed were seasonal, habitat, or host plant generalists (Table 2). Specifically, just three species had single broods per year and only five species had restricted habitat requirements. Although nine butterfly species utilized 10 or fewer larval host plants, many of the required host plants used by these species are common in urban areas (e.g. nettles, elms, violets, crabgrass). Observed butterfly species richness ranged from 3 to 16 species/taxa per garden (mean $\pm \mathrm{SD}=9 \pm 4$ ). The Chao2 estimate of butterfly species richness ranged from 7 to 41 (mean $\pm \mathrm{SD}=16 \pm 8$ ) species per garden.

A total of 1,145 collected bees were identified to 54 species (including Apis mellifera). We more fully discuss the composition and ecological characteristics of these bee species in Matteson et al. (2008). Briefly however, the most abundant species were two exotic yellowfaced bees (Colletidae), Hylaeus leptocephalus and H. hyalinatus, and the native bumble bee Bombus impatiens. Native, small-bodied bees in the genus Lasioglossum were also prevalent. Observed bee species richness ranged from 7 to 29 species per garden (mean \pm $\mathrm{SD}=18 \pm 7$ ) whereas the Chaol estimate of bee species richness ranged from 7 to 46 species per garden (mean $\pm \mathrm{SD}=25 \pm 11)$.

Models of insect richness

For butterfly richness, the most informative model included just floral area and sunlight $\left(\Delta \mathrm{AIC}_{\mathrm{c}}=0.0 ; W_{i}=59 \%\right.$, adj. $R^{2}=0.601$; Table 3$)$. There was also some support for a simple univariate model including only garden floral area $\left(\Delta \mathrm{AIC}_{\mathrm{c}}=1.39 ; W_{i}=30 \%\right.$, adj. $R^{2}=$ 0.513). The next most supported model included floral area, sunlight, and garden age (which exhibited a negative relationship with butterfly richness), but this model garnered just $10 \%$ of the support (Table 3). All other multivariate models of butterfly species richness were not well-supported (Akaike weights less than 5\%).

For bee species richness, there was nearly equivalent support for two models. One model included total garden area, floral area, and sunlight $\left(\triangle \mathrm{AIC}_{\mathrm{c}}=0.0 ; W_{i}=35 \%\right.$, adj. $R^{2}=0.678$; Table 4). The other model included just total garden area and floral area $\left(\Delta \mathrm{AIC}_{\mathrm{c}}=0.18\right.$; $W_{i}=32 \%$, adj. $R^{2}=0.622$; Table 4 ). Together, these two models contained $67 \%$ of the support and each had more than two times the support of any subsequent model. The number of building units surrounding gardens at the $500 \mathrm{~m}$ scale was present in two models (one with $12 \%$ of the support, and one with $9 \%$ of the support) whereas garden canopy cover was included in a model that garnered $10 \%$ of the support.

\section{Discussion}

Influence of local variables on insect richness

As expected, floral area per garden had the greatest influence on both butterfly and bee species richness. Strong relationships between local plant/floral resources and butterfly and 


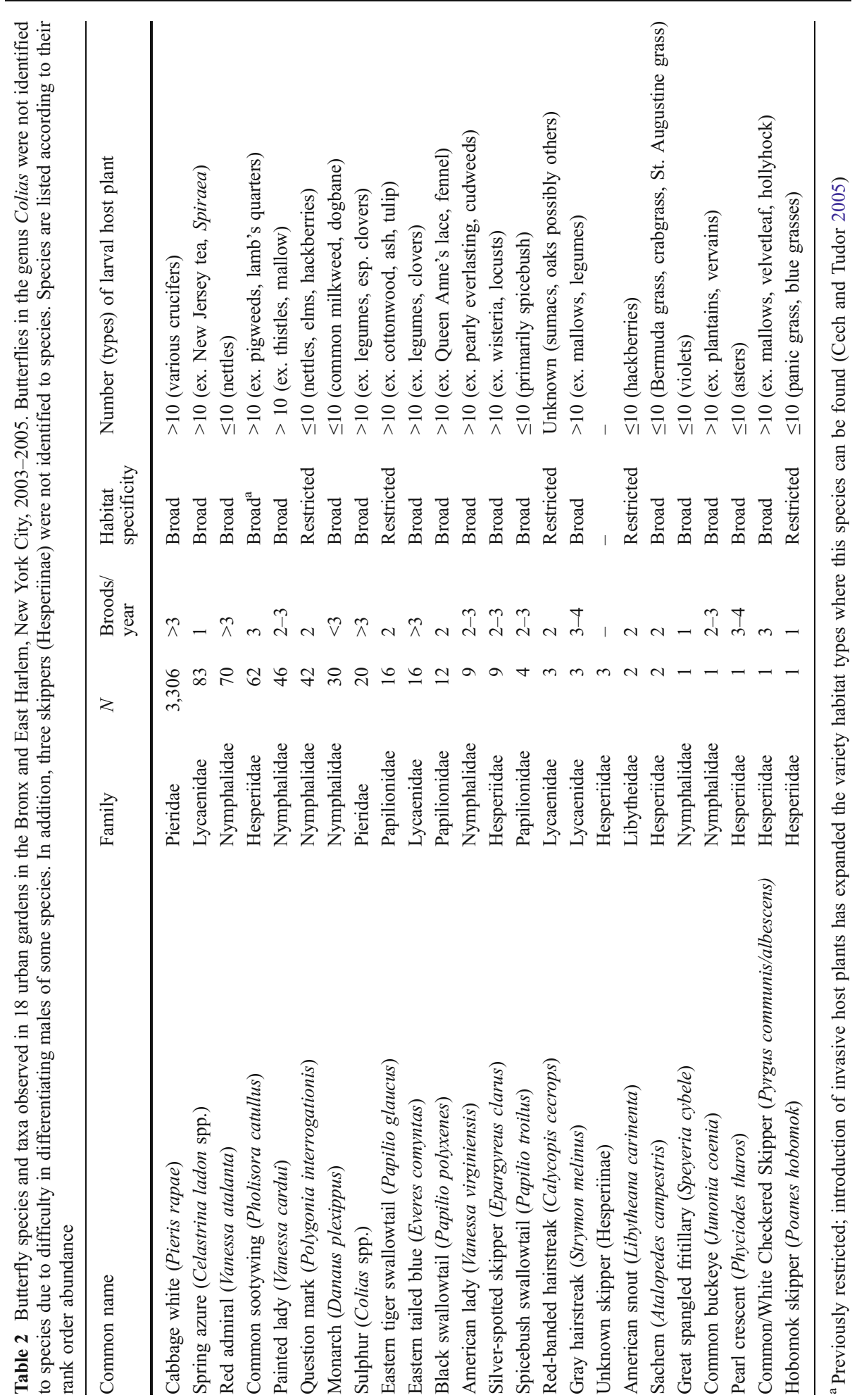


Table 3 Models ranked by $\triangle \mathrm{AIC}_{\mathrm{c}}$ explaining butterfly species richness in urban community gardens of New York City. Reported statistics include $\Delta \mathrm{AIC}_{\mathrm{c}}, W_{i}$ (Akaike weight), $\mathrm{AIC}_{\mathrm{c}}, \mathrm{RSS}$ (residual sum of squares), $K$ (number of parameters including the constant and the estimate of residual variance) and Adj. $R^{2}$ (adjusted $R^{2}$ ). The sample size for all models was $n=18$. Regression equations with standardized coefficients for included variables are shown for models with $>5 \%$ of the support based on Akaike weights $\left[W_{i}\right.$ ] (shaded models). See Methods for descriptions of all model variables

\begin{tabular}{|c|c|c|c|c|c|c|}
\hline Model Parameters & $\triangle \mathrm{AICc}$ & $W i$ & $\mathrm{AICc}$ & RSS & $K$ & Adj. $R^{2}$ \\
\hline $\begin{array}{l}\text { Floral area }+ \text { sunlight } \\
{\left[\log _{10}(y)=0.527 * \text { floral area }+0.387 * \text { sunlight }{ }^{\wedge} 3\right]}\end{array}$ & 0.00 & $59 \%$ & -68.07 & 0.222 & 4 & 0.601 \\
\hline $\begin{array}{l}\text { Floral area } \\
{\left[\log _{10}(y)=0.736 * \text { floral area }\right]}\end{array}$ & 1.39 & $30 \%$ & -66.68 & 0.289 & 3 & 0.513 \\
\hline $\begin{array}{l}\text { Floral area }+ \text { sunlight }+ \text { garden age } \\
{\left[\log _{10}(y)=0.533 * \text { floral area }+0.356 * \text { sunlight }{ }^{\wedge} 3-0.041 * \text { garden age }\right]}\end{array}$ & 3.55 & $10 \%$ & -64.52 & 0.217 & 5 & 0.549 \\
\hline $\begin{array}{l}\text { Floral area }+ \text { sunlight }+ \text { garden age }+ \text { total garden area }+ \text { building units } \\
(500 \mathrm{~m})\end{array}$ & 13.60 & $<1 \%$ & -54.47 & 0.215 & 7 & 0.515 \\
\hline $\begin{array}{l}\text { Floral area }+ \text { sunlight }+ \text { garden age }+ \text { total garden area }+ \text { building units } \\
(500 \mathrm{~m})+\text { presence of wild/unmanaged areas }\end{array}$ & 16.80 & $<1 \%$ & -51.27 & 0.176 & 8 & 0.524 \\
\hline $\begin{array}{l}\text { All variables except garden canopy cover, gardenH, green space } \\
(500 \mathrm{~m}) \text {, building units }(200 \mathrm{~m}) \text { and green space }(200 \mathrm{~m})\end{array}$ & 25.30 & $<1 \%$ & -42.77 & 0.176 & 9 & 0.524 \\
\hline All variables except garden canopy cover and gardenH & 67.05 & $<1 \%$ & -1.02 & 0.140 & 12 & 0.459 \\
\hline All variables except garden canopy cover & 96.87 & $<1 \%$ & 28.79 & 0.134 & 13 & 0.396 \\
\hline Global (all 12 variables) & 145.45 & $<1 \%$ & 77.38 & 0.117 & 14 & 0.367 \\
\hline
\end{tabular}

Table 4 Models ranked by $\triangle \mathrm{AIC}_{\mathrm{c}}$ explaining bee species richness in urban community gardens of New York City. Reported statistics include $\Delta \mathrm{AIC}_{\mathrm{c}}, W_{i}$ (Akaike weight), $\mathrm{AIC}_{\mathrm{c}}, \mathrm{RSS}$ (residual sum of squares), $K$ (number of parameters including the constant and the estimate of residual variance) and Adj. $R^{2}$ (adjusted $R^{2}$ ). The sample size for all models was $n=18$. Regression equations with standardized coefficients for included variables are shown for models with $>5 \%$ of the support based on Akaike weights $\left[W_{i}\right]$ (shaded models). See Methods for descriptions of all model variables

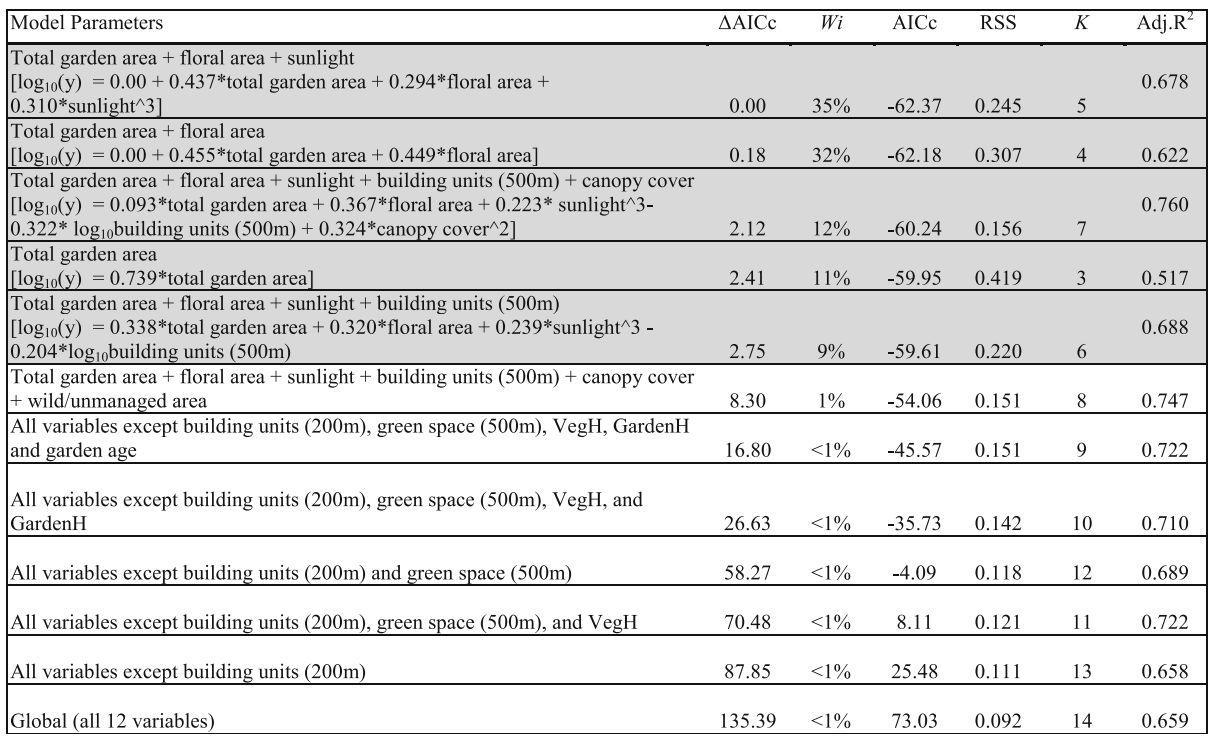


bee diversity have also been found for large parks of New York City (Giuliano et al. 2004), residential gardens of Berkeley (Frankie et al. 2005), grassland fragments in Boulder (Kearns and Oliveras 2009), and meadows habitats in the Greater Boston Area (Clark et al. 2007). We did not measure floral diversity, which has been shown to have a strong influence on pollinator diversity (Potts et al. 2004). All of the butterflies and most of the bees $(89 \%)$ encountered in these gardens are generalist floral feeders as adults. Thus, it might be interesting to evaluate the influence of floral abundance relative to floral diversity in this or other urban settings characterized by generalist floral feeders.

The most highly supported models for both butterfly and bee species richness also included the availability of sunlight within gardens. In contrast to open meadow habitats or even single-family residential gardens, the gardens of this study were commonly obstructed by tall apartment buildings. Indeed, there were negative associations between sunlight availability and the number of building units surrounding gardens at both the $200 \mathrm{~m}(r=$ $-0.472)$ and $500 \mathrm{~m}$ scales $(r=-0.458)$. Shading due to buildings results in limited photosynthetic photon flux relative to shade from deciduous trees (Bell et al. 2000) and thus may more severely limit plant growth and/or opportunities for bees and butterflies to increase body temperature via passive basking in gardens. Although it is difficult to increase sunlight for ground-level urban gardens, there is increasing interest in using green roofs to augment habitat area for urban wildlife (Oberndorfer et al. 2007), including bees (Colla et al. 2009). Because sunlight is less limited on most rooftops, large, florally rich green roofs may provide important bee and butterfly habitat, especially in inner-city areas where ground-level habitats are often shaded by buildings.

While both bees and butterflies responded to sunlight and floral area, bees responded to several additional garden variables. Specifically, there was marginal support for a model of bee species richness including garden canopy cover, and bee species richness also responded positively to total garden area and the presence of wild/unmanaged areas in the garden (Fig. 2). The response of bees, but not butterflies, to these variables likely reflects general differences in the mobility and life history requirements of bees and butterflies. Specifically, many of the butterflies found in these gardens are highly mobile, and thus unlikely to remain in gardens for long periods. In contrast, bees forage for nectar and pollen within a fixed distance from a centrally located nest. Many of the bee species encountered in this study have limited foraging ranges $(<500 \mathrm{~m}$; body sizes of species listed in Matteson et al. 2008 applied to data provided in Greenleaf et al. 2007), suggesting that many of the bee species nest within or near gardens. Because most of the bee species encountered in our study gardens construct nests in hollow plant stems or in soil (Matteson et al. 2008), a larger total garden, or having more wild/unmanaged areas of the garden (where trampling/ turning of soil and pruning of plant debris is limited) may better enable larva/pupa to develop (Buchmann and Nabhan 1997). In support of this idea, Smith et al. (2006) found bumble bee species richness to be negatively associated with intensity of garden management. None of the gardens of this study included bee or butterfly nesting blocks, which may be an additional method for increasing local species richness (Gaston et al. 2005).

\section{Influence of landscape variables on insect richness}

We initially hypothesized that surrounding green space would be especially influential in this setting, due to its limited availability (range of $\sim 10-30 \%$ green space at the $500 \mathrm{~m}$ scale). Landscape green space, however, had little influence on bee or butterfly richness. This may have been because our measure of green space included closely mown lawns and 
tree cover, which may be poor proxies for bee or butterfly larval, nesting or floral resources. Alternately, it may be that landscape-sensitive species have already been locally extirpated from heavily developed neighborhoods of this study, as has been suggested for insect taxa in other cities (Kozlov 1996; Connor et al. 2003). For instance, despite sampling these gardens for 4 years, we encountered just five of the 16 bumble bee species known to inhabit southern New York state (John S. Ascher, personal communication), and similar reductions in bumble bees have been noted in San Francisco, USA (McFrederick and Lebuhn 2006) and Stockholm, Sweden (Ahrné et al. 2009). Overall, twice as many bee species were found in private gardens in less developed suburbs just $50 \mathrm{~km}$ north of our study sites (Fetridge et al. 2008). Similarly, we found just 24 of the 120 butterfly species reported to inhabit a 50mile radius around New York City (Cech 1991) and most were seasonal or habitat generalists, or utilize host plants that are fairly common in the urban landscape (Table 2). In the Greater Boston Area, rare and specialist butterfly species exhibited the strongest decrease with increasing urbanization (Clark et al. 2007), suggesting that generalist species may be less responsive to limitations in landscape green space. Di Mauro et al. (2007), however, demonstrated that generalist butterflies also may decrease with urbanization (decreasing green space) in some garden types.

Collinge et al. (2003) and Kearns and Oliveras (2009) also failed to find a relationship between the proportion of the landscape that was developed and butterfly species richness or bee species richness. These authors, however, concluded that the degree of urbanization proximal to their study sites (grassland habitats located at the edge of urban development, outside of Boulder, Colorado) was insufficient to result in a measureable decrease in species richness. This suggests that traditional measures of landscape context (e.g. green space, semi-natural habitat) may have neutral effects both in highly developed areas (such as this study where there are few remaining landscape-sensitive species) as well as in relatively less developed areas at the outskirts of urban development (where few landscape-sensitive species may have been lost). Studies conducted across a wider range of urban development with local variables held close to constant (i.e., little variation in area or floral resources), may find a stronger impact of landscape green space (Winfree et al. 2007; Ahrné et al. 2009), which may exert a nonlinear influence on insect richness. For instance, Öckinger et al. 2009 found butterfly richness of urban parks to increase with green space in a system with $10-80 \%$ green space at the $1,000 \mathrm{~m}$ scale (in contrast this study, where there was a range of just $\sim 10-30 \%$ green space at the $500 \mathrm{~m}$ scale).

We found some support for the hypothesis that the number of building units surrounding gardens at the $500 \mathrm{~m}$ scale negatively influences bee species richness. The number of building units was not correlated with green space at the $500 \mathrm{~m}$ scale $(r=0.02)$, indicating that there are mechanisms other than a reduction in green space involved in this relationship. The number of building units at the $500 \mathrm{~m}$ scale was, however, negatively correlated with garden sunlight availability $(r=-0.458)$, suggesting that the effect may be due to shading of both the focal garden (as discussed above) and surrounding landscape. Another possibility is that floral resources are reduced, independent of our measure of "green space", around large apartment buildings relative to single-family residences. In support of this idea, green space surrounding several large housing projects proximal to these gardens was largely composed of lawns interspersed with sycamore trees and Taxus bushes, and few floral resources (KCM, personal observation). This suggests that different types of urban housing development may have very different effects on bee or butterfly species richness. Specifically, bee and butterfly diversity might be optimized near low-density or singlefamily homes with large, florally rich gardens (Winfree et al. 2007; Fetridge et al. 2008; Frankie et al. 2009), but limited in high-density neighborhoods with few floral resources. 


\section{Conclusion}

The results of this study indicate that sunlight and floral abundance are major factors limiting pollinator diversity in urban gardens located in heavily developed neighborhoods. The general patterns hold true in posthoc analyses of observed, rather than estimated, species richness and in analyses of specific-species groupings such as just native or "largebodied" bees (KCM, unpublished data). This suggests that rooftop gardens and other "open" urban habitats might be managed to benefit local pollinator diversity by increasing floral area, even if seemingly "isolated" within heavily developed neighborhoods. Such actions may be difficult to implement, however, in heavily developed neighborhoods where sunlight is limited by the vertical extent of tall buildings. In addition, the maximum level of species richness may be restricted to the pool of species that linger within heavily developed neighborhoods. While we did not find the amount of green space in a $500 \mathrm{~m}$ radius to have a major influence in this setting, additional bee and butterfly species may only persist in neighborhoods with a green space threshold greater than the $10-30 \%$ range (at the $500 \mathrm{~m}$ radius scale) of this study. Therefore, larger scale efforts to implement floral plantings into areas of the urban landscape that receive full sun exposure (e.g. rooftop gardens, building terraces with southern exposure), in addition to increasing connectivity to species rich peri-urban areas (Snep et al. 2006), may be required to attract and benefit a greater diversity of bees and butterflies.

Acknowledgements We thank the New York Restoration Project, Trust for Public Land and the following community gardeners: C. Agripino, E. Butler, A. Campos, O. Delvalle, F. Espinoza, F. Mastrota, E. Nemley, W. Parker, J. Plewka, O. Seijo, I. Smith, Taz and K. Washington. John S. Ascher of the American Museum of Natural History identified the bulk of the bees, for which we are most grateful. We also thank Sam Droege of the United States Geological Survey and Parker Gambino for additional help sorting and identifying Hymenoptera. This work was partially supported by funds from a Lindbergh Foundation Grant to G.A.L. This document represents contribution 249 of the Louis Calder Biological Field Station.

Open Access This article is distributed under the terms of the Creative Commons Attribution Noncommercial License which permits any noncommercial use, distribution, and reproduction in any medium, provided the original author(s) and source are credited.

\section{References}

Ahrné K, Bengtsson J, Elmqvist T (2009) Bumble bees (Bombus spp) along a gradient of increasing urbanization. PLoS ONE 4:e5574

Bell GE, Danneberger TK, McMahon MJ (2000) Spectral irradiance available for turfgrass growth in sun and shade. Crop Sci 40:189-195

Bolund P, Hunhammar S (1999) Ecosystem services in urban areas. Ecological Economics 29:293-301

Brock JP, Kaufman K (2003) Butterflies of North America. Houghton Mifflin Company, Singapore

Brose U, Martinez ND (2004) Estimating the richness of species with variable mobility. Oikos 105:292-300

Buchmann SL, Nabhan GP (1997) The forgotten pollinators. Island, Washington

Burnham KP, Anderson DR (1998) Model selection and inference: a practical information-theoretic approach. Springer, New York

Cech R (ed) (1991) A distributional checklist of the butterflies and skippers of the New York City area (50mile radius) and Long Island. New York City Butterfly Club (available at http://www.butterfliesarestillfree. com/publications-distributional.html)

Cech R, Tudor G (2005) Butterflies of the East Coast, an observer's guide. Princeton University Press, Princeton 
Clark PJ, Reed JM, Chew FS (2007) Effects of urbanization on butterfly species richness, guild structure, and rarity. Urban Ecosystems 10:321-337

Colla SR, Willis E, Packer L (2009) Can green roofs provide habitat for urban bees (Hymenoptera: Apidae)? Cities and the Environment 2:article 4, 12 pp, http://escholarship.bc.edu/cate/vol12/iss11/14

Collinge SK, Prudic KL, Oliver JC (2003) Effects of local habitat characteristics and landscape context on grassland butterfly diversity. Conserv Biol 17:178-187

Connor EF, Hafernick J, Levy J, Moore VL, Rickman JK (2003) Insect conservation in an urban biodiversity hotspot: the San Francisco Bay Area. J Insect Conserv 6:247-259

Council on the Environment of New York City (2006) Open accessible space information system for New York City. CUNY Mapping Service at the Center for Urban Research. The Graduate Center / CUNY

Di Mauro D, Dietz T, Rockwood L (2007) Determining the effect of urbanization on generalist butterfly species diversity in butterfly gardens. Urban Ecosystems 10:427-439

Fetridge E, Ascher JS, Langellotto GA (2008) The bee fauna of residential gardens in a suburb of New York City (Hymenoptera: Apoidea). Ann Entomol Soc Am 101:1067-1077

Frankie GW, Thorp RW, Schindler M, Hernandez J, Ertter B, Rizzardi M (2005) Ecological patterns of bees and their host ornamental flowers in two northern California cities. Journal of the Kansas Entomological Society 78:227-246

Frankie GW, Thorp RW, Hernandez J, Rizzardi M, Ertter B, Pawelek JC, Witt SL, Schindler M, Coville R, Wojcik VA (2009) Native bees are a rich natural resource in urban California gardens. California Agriculture 63:113-120

Gaston KJ, Smith RM, Thompson K, Warren PH (2005) Urban domestic gardens (II): experimental tests of methods for increasing biodiversity. Biodivers Conserv 14:395-413

Gathmann A, Tscharntke T (2002) Foraging ranges of solitary bees. J Anim Ecol 71:757-764

Giuliano WM, Accamandon AK, McAdams EJ (2004) Lepidoptera-habitat relationships in urban parks. Urban Ecosystems 7:361-370

Greenleaf SS, Williams NM, Winfree R, Kremen C (2007) Bee foraging ranges and their relationship to body size. Oecologia 153:589-596

Hurvich CM, Tsai CL (1989) Regression and time series model selection in small samples. Biometrika 76:297-307

Kearns CA, Oliveras DM (2009) Environmental factors affecting bee diversity in urban and remote grassland plots in Boulder, Colorado. J Insect Conserv 13:655-665

Kitahara M, Fujii K (1994) Biodiversity and community structure of temperate butterfly species within a gradient of human disturbance: an analysis based on the concept of generalist vs. specialist strategies. Researches on Population Ecology 36:187-199

Kozlov MV (1996) Patterns of forest insect distribution within a large city: microlepidoptera in St Petersburg, Russia. J Biogeogr 23:95-103

Levins R (1969) Some demographic and genetic consequences of environmental heterogeneity for biological control. Bulletin of the Entomological Society of America 15:237-240

Mac Nally R (2002) Multiple regression and inference in ecology and conservation biology: further comments on identifying important predictor variables. Biodivers Conserv 11:1397-1401

Matteson KC (2007) Diversity and conservation of insects in urban gardens: theoretical and applied implications. Dissertation, Department of Biological Sciences, Fordham University, Bronx

Matteson KC, Langellotto GA (2009) Bumble bee abundance in New York City urban gardens: implications for urban agriculture. Cities and the Environment 2:article 5, 12 pp, http://escholarship.bc.edu/cate/ vol12/iss $11 / 15$

Matteson KC, Ascher JS, Langellotto GA (2008) Bee richness and abundance in New York City urban gardens. Ann Entomol Soc Am 101:140-150

McFrederick QS, Lebuhn G (2006) Are urban parks refuges for bumble bees Bombus spp. (Hymenoptera: Apidae)? Biol Conserv 129:372-382

McIntyre NE (2000) Ecology of urban arthropods: a review and a call to action. Ann Entomol Soc Am 93:826-835

McIntyre NE, Hostetler ME (2001) Effects of urban land use on pollinator (Hymenoptera: Apoidea) communities in a desert metropolis. Basic and Applied Ecology 2:209-218

McKinney ML (2002) Urbanization, biodiversity and conservation. Bioscience 52:883-890

McKinney ML (2006) Urbanization as a major cause of biotic homogenization. Biol Conserv 127:247-260

McKinney ML (2008) Effects of urbanization on species richness: A review of plants and animals Urban Ecosystems 11:1573-1642

Miller JR (2005) Biodiversity conservation and the extinction of experience. Trends in Ecology and Evolution 20:430-434

Myeong S, Nowak DJ, Hopkins PF, Brock RH (2001) Urban cover mapping using digital, high-spatial resolution aerial imagery. Urban Ecosystems 5:243-256 
New Yorkers For Parks (2005) District profiles 2005, your parks, your playgrounds. New Yorkers for Parks, New York

Oberndorfer E, Lundholm J, Bass B, Coffman RR, Doshi H, Dunnett N, Gaffin S, Köhler M, Liu KKY, Rowe B (2007) Green roofs as urban ecosystems: ecological structures, functions, and services. Bioscience 57:823-833

Öckinger E, Dannestam A, Smith HG (2009) The importance of fragmentation and habitat quality of urban grasslands for butterfly diversity. Landscape and Urban Planning 93:31-37

Potts SG, Vulliamy B, Roberts S, O'Toole C, Dafni A, Ne'eman G, Willmer PG (2004) Nectar resource diversity organises flower-visitor community structure. Entomologia Experimentalis et Applicata 113:103-107

Pyle RM (1978) The extinction of experience. Horticulture 56:64-67

Ruszczyk A, De Araujo AM (1992) Gradients in butterfly species diversity in an urban area in Brazil. Journal of the Lepidopterists' Society 46:255-264

Scott JA (1975) Flight patterns among eleven species of diurnal Lepidoptera. Ecology 56:1367-1377

Smith RM, Warren PH, Thompson K, Gaston KJ (2006) Urban domestic gardens (VI): environmental correlates of invertebrate species richness. Biodivers Conserv 15:1572-9710

Snep RPH, Opdam PFM, Baveco JM, WallisDeVries MF, Timmermans W, Kwak RGM, Kuypers V (2006) How peri-urban areas can strengthen animal populations within cities: a modeling approach. Biol Conserv 127:345-355

Sokal RR, Rohlf F (1995) Biometry. Freeman, New York

Systat (2004) System for windows: statistics, version 11. Systat, Inc., Richmond

United Nations Population Division (2006) World urbanization prospects: the 2005 revision. United Nations, Department of Economic and Social Affairs, New York

United States Census Bureau (2006) 2006 Population estimates. U.S. Census Bureau, Washington

Walther BA, Moore JL (2005) The concepts of bias, precision and accuracy, and their use in testing the performance of species richness estimators, with a literature review of estimator performance. Ecography 28:815-829

Werrell PA, Langellotto GA, Morath SU, Matteson KC (2009) The influence of garden size and floral cover on pollen deposition in urban community gardens. Cities and the Environment 2:article 6, $16 \mathrm{pp}$, http:// escholarship.bc.edu/cate/vol12/iss $11 / 16$

Winfree R, Dushoff J, Crone EE, Schultz CB, Budny RV, Williams NM, Kremen C (2005) Testing simple indices of habitat proximity. Am Nat 165:707-717

Winfree R, Griswold T, Kremen C (2007) Effect of human disturbance on bee communities in a forested ecosystem. Conserv Biol 21:213-223 